\title{
Power-Sharing Control in Bearingless Multi-Sector and Multi-Three-Phase Permanent Magnet Machines
}

\author{
Giacomo Sala, Member, IEEE, Giorgio Valente, Mauro Di Nardo, Member, IEEE, Michele Degano, \\ Member, IEEE, Pericle Zanchetta, Fellow, IEEE, and Chris Gerada, Senior Member, IEEE.
}

\begin{abstract}
This paper deals with the power-sharing control of bearingless multi-sector and multi-three-phase permanent magnet machines. The proposed control strategy allows to distribute the power flows among the three-phase inverters supplying the machine during bearingless operation of the drive. The control technique is based on the extension of the vector space decomposition modeling approach. The components producing the electromagnetic torque, i.e. the $q$-axis currents, are controlled independently from the $d$-axis ones, also with the aim of managing the power flows among the three-phase systems. Conversely, the $d$-axis currents are exploited for the generation of the radial forces needed to levitate the rotor, while considering the compensation of the forces caused by the q-axis currents in case of unbalanced power sharing strategy. The validity of the proposed method is confirmed by simulations and experimental tests on a prototyped bearingless multisector permanent magnet synchronous machine. The proposed approach is a contribution to the development of advanced control systems employing multiphase drives in the field of bearingless and multiport applications.
\end{abstract}

Index Terms - Bearingless machines, force control, machine vector control, magnetic levitation, multiphase drives, permanent magnet machines, power-sharing, variable speed drives.

\section{NOMENCLATURE}

$p \quad$ Pole pair number.

$P \quad$ Subscript used to identify the sub-windings under the same $P^{\text {th }}$ sector $(P=1,2, \ldots, p)$.

$N_{T} \quad$ Number of three-phase star connected windings located under each pole pair (sector).

$T \quad$ Subscript used to distinguish the sub-windings under the same $P^{\text {th }}$ sector $\left(T=1,2, \ldots, N_{T}\right)$.

$\bar{\imath}_{T, P} \quad$ Current space vector of each $T^{\text {th }}$ three-phase sub-winding under the $P^{\text {th }}$ sector.

Manuscript received April 27, 2020; revised June 10, 2020 and July 22, 2020; accepted September 01, 2020. (Corresponding author: Giacomo Sala).

G. Sala is with the Department of Electrical, Electronic and Information Engineering "Guglielmo Marconi," University of Bologna, 40136 Bologna, Italy (e-mail:, giacomo.sala5@unibo.it).

G. Valente is with the Innovation and Research Department, Romax Technology, part of Hexagon's Manufacturing Intelligence division, Nottingham, UK (e-mail: giorgio.valente@ romaxtech.com).

M. Di Nardo, M. Degano, P. Zanchetta and C. Gerada are with the PEMC Group, Department of Electrical and Electronic Engineering, The University of Nottingham, NG7 2RD, Nottingham, UK (e-mail: mauro.dinardo4@nottingham.ac.uk, michele.degano@nottingham.ac.uk, chris.gerada@nottingham.ac.uk, pericle.zanchetta@nottingham.ac.uk).

M. Degano and C. Gerada are also with the Key Laboratory of More Electric Aircraft Technology of Zhejiang Province, PEMC Group, University of Nottingham Ningbo Campus, UNNC, China.
$M \quad$ Subscripts used to identify the three phases of each sub-winding $(M=U, V, W)$.

$i_{T, P, M} \quad$ Current of the $M^{\text {th }}$ phase of the $T^{\text {th }}$ three-phase sub-winding under the $P^{\text {th }}$ sector.

$\rho \quad$ Order of the space vector, and order of the related harmonic of the stator magnetomotive force distribution.

$\bar{\imath}_{\rho} \quad$ Current space vector of space $\rho^{\text {th }}$.

$f_{e(m)}, \omega_{e(m)}$ Fundamental electrical (mechanical) frequency and angular speed.

$\vartheta_{m} \quad$ Rotor angular position.

$j \quad$ Imaginary unit.

* Conjugate operator.

$T \quad$ Electromagnetic torque.

$k_{T} \quad$ Torque constant.

$\bar{F}_{\rho} \quad$ Radial force contribution related to the $\rho^{\text {th }}$ space (in its $x$-y components: $\bar{F}_{\rho}=F_{\rho, x}+j F_{\rho, y}$ ).

$k_{F, \rho} \quad$ Radial force constant associated with the contribution related to the $\rho^{\text {th }}$ current space vector.

$c_{m, \rho}, c_{n, \rho}$ Constants introduced to link the modular threephase quantities with the multiphase ones.

$d, q \quad$ Subscripts used to identify the variables defined in the synchronous reference frame.

$K_{T, P, d(q)} \quad d$ (or $q$ ) axis sharing coefficient of the $T^{\text {th }}$ threephase sub-winding under the $P^{\text {th }}$ sector.

$\bar{K}_{\rho, d(q)_{ \pm}} d$ (or $q$ ) axis current-sharing complex control variable related to the $\rho^{\text {th }}$ vector space, with + and - subscripts used to identify the sharing complex variables that are multiplied by $e^{j p \vartheta_{m}}$ or $e^{-j p \vartheta_{m}}$ in (12), respectively.

$\bar{F}_{\text {sh }} \quad$ Radial force generated by a conventional powersharing control algorithm.

$R_{S} \quad$ Phase resistance.

$A, B, C$ Subscripts used to identify the sub-windings under the three sectors of the considered triple three-phase machine.

\section{INTRODUCTION}

$\mathrm{M}$ ultiphase drive technologies are rapidly reaching different industrial markets, ranging from high-power and high-voltage generators [1]-[4] to low-voltage hybrid powertrains for automotive applications [5], [6].

The ever increasing interest for multiphase drives, i.e. with more than three phases, is related to the power split (current and/or voltage) among more phases, increased power density, and enhanced reliability [7]-[9]. Therefore, in high-current and high-voltage applications the multi-level converter and 


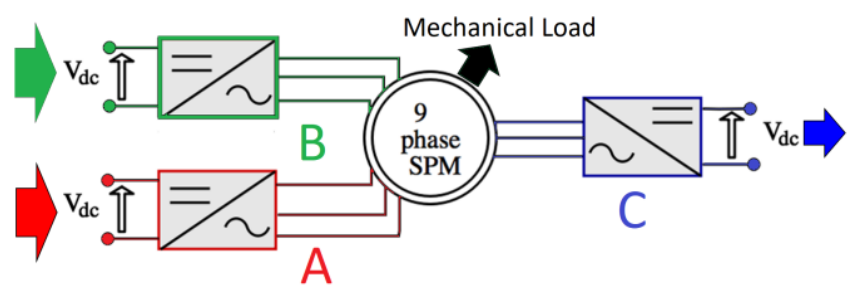

Fig. 1 - Power-sharing concept. The input and output power flows are displayed with colored arrows. The power flow of inverter $C$ in the figure (blue arrow) is opposite to the ones of inverters $A$ and $B$.

the multi-phase winding are becoming common solutions, allowing to enhance the drives performance while dealing with the technological limitations of the available high-power electronic components [10], [11]. In other application fields such as electrical transportation and safety critical systems, the multiphase architecture has been introduced for its internal redundancy [12]. In addition, it presents the opportunity of connecting different inverters, each supplying independent sets of phases, to separated power lines, as illustrated in Fig. 1 for a triple three-phase drive [13]. This control possibility, also known under the name of power-sharing capability of multiphase drives, has been analyzed in-depth in recent research studies [14]-[16].

In the field of bearingless electrical machines, the use of multiphase windings was firstly proposed by Hermann in 1973 [17]. Notable developments and industrial applications of Bearingless Motors (BMs) are well summarized in [18] [21]. A variety of bearingless designs has been proposed from the literature, all able to simultaneously generate a flux distribution with periodicity $p$ and $p \pm 1$ needed to produce torque and radial force, respectively. To differentiate among them, it is possible to separate the research studies into two main categories based on the winding arrangement. The first one makes use of two sets of windings, one to generate the torque and the other to produce the force needed for the bearingless operation [22], [23]. The second relies on a combined winding, typically a multiphase one, where all the phases simultaneously contribute to both spin and levitate the rotor [24], [25]. Among the combined winding it is worth mentioning also bridge and parallel path layouts. These configurations have the potential advantage of being "novoltage" designs, since the suspension terminals do not see an induced voltage by the rotor flux (motional electromotive force) [26], [27]. The multiphase solution is chosen in this paper, instead of a separate winding arrangement, because the stator slot area hosting the suspension winding can cover about $25-40 \%$ of the available space. This leads to an oversize of the winding to ensure a reliable force control in all working conditions [20]. Also, multiphase BMs exhibit better fault tolerant capabilities than dual winding ones, because the torque and force controls can still be performed in case of some fault conditions. In fact, contact bearings are one of the most critical parts of an electric motor subject to failure, and the enhancement of the fault tolerance capability of BMs is a promising research topic for the development of safety critical architectures.

Further investigations on bearingless machines have been carried out in terms of machine design [20], [21], [28], [29], control performance [30], [31] and fault tolerant operation [32], [33]. Bearingless systems have been proposed for commercial applications such as compressors, spindles, drills, flywheels, and turbine generators, where high and ultra-high rotation speed is a requirement [34]. Disk drives with speed up to $150 \mathrm{krpm}$ have been reached by employing sliced rotors for high purity and special chemical demand [35], whereas separate winding motors for laser scanning or reaction wheels (proposed for satellite attitude control systems) are tested in the range of 300-500 krpm in [22], [36]. To the best of the authors' knowledge, the highest speed reached by an electrical motor is mentioned in [37], where the authors present a magnetically levitated spinning ball motor able to reach up to $40260000 \mathrm{rpm}$. Also miniature medical pumps [38], highpurity mixers [39] and machines with rotors operating in contact with aggressive fluids [40] are further important fields of application.

Although the industrial application of bearingless motors is still limited to low power applications, they are considered promising substitutes of Active Magnetic Bearings (AMB) in high-power and high-speed applications, where the extra volume and overlength of AMBs limits the speed, due to rotodynamic challenges [41], and the power density of the overall system. In fact, the lower efficiency and power rating of existing bearingless motor prototypes make this technology still not ready for industrialization in conventional applications [20]. To enhance the power of bearingless motors, also considering the inverter limitations and fault tolerant requirements, the multi-three-phase winding solution seems suitable for high power-rating bearingless applications. Also, the permanent magnet topology of bearingless motor has been preferred in this research for its high efficiency and torque density [28].

This paper focuses on the power-sharing control of bearingless multi-sector and multi-three-phase machines. The control is developed considering the machine as a whole system, following the multiphase approach known as Vector Space Decomposition (VSD). The equations are written in terms of independent current vectors, directly related to the control of specific space harmonics of the airgap magnetic field. After introducing the equations describing the electromagnetic behavior of the machine (in Section II), the power-sharing and the control algorithm of the drive are presented (Section III-IV) and validated via FE simulations. Section $V$ reports the numerical simulations and experimental tests performed on a prototyped bearingless machine.

\section{TORQUE AND RADIAL FORCE EQUATIONS}

This section presents the methodology used for the analysis of torque and radial force production in multiphase machines. A model is developed by means of a VSD approach, widely used for the representation of polyphase systems. The presented theory focuses on Multi-Sector Permanent Magnet (MSPM) machines, assuming as negligible the saturation of the magnetic materials and the slotting effect, and a prevalence of the fundamental component of the airgap flux density produced by of the rotor permanent magnets.

The VSD approach allows describing the torque and radial force of a multiphase electric drive as a function of specific current space vectors according to the machine topology [42][47]. The currents of a MSPM machine, made of $N_{T}$ threephase star connected windings located under each $P^{\text {th }}$ sector 
(or pole pair) of the machine, can be described by the conventional three-phase space vector representation of each three-phase sub-winding (with phases $T, P, U, T, P, V$, and $T, P, W)$ defined as follows:

$$
\bar{\imath}_{T, P}=\frac{2}{3}\left(i_{T, P, U}+i_{T, P, \nu} e^{j \frac{2 \pi}{3}}+i_{T, P, W} e^{j \frac{4 \pi}{3}}\right)
$$

with $T=1,2, \ldots, N_{T}$ and $P=1,2, \ldots, p$.

A reasonable assumption is to consider each three-phase sub-winding symmetrically distributed under its pole pair.

Also, in case of more three-phase subwindings under the same pole pair, the shift between each three-phase subwinding and the following one is assumed to be the same. For example, in case of three three-phase subsystems under each pole pair, the second and the third would be placed shifted by 20 and 40 electrical degrees with respect to the first one, respectively. This choice can be adopted to enhance the torque performance of the multiphase machine keeping the multisector layout.

In case of different winding arrangements, the methodology presented in this paper can still be used by adapting the space vector transformations to the considered configuration.

Pursuing the VSD approach, the current space vectors of the considered multi-sector machine can be defined as follows:

$$
\begin{aligned}
\bar{\iota}_{\rho}=\frac{2}{3 p N_{T}} \sum_{T=1}^{N_{T}} \sum_{P=1}^{p}\left(i_{T, P, U}-i_{T, P, V} e^{-j \rho \frac{2 \pi}{6 p}}\right. \\
\left.-i_{T, P, W} e^{j \rho \frac{2 \pi}{6 p}}\right) e^{j \rho \frac{2 \pi(T-1)}{6 p N_{T}}} e^{j \rho \frac{2 \pi(P-1)}{p}} .
\end{aligned}
$$

Transformation (2) describes the general $\rho^{\text {th }}$ current space vector of the machine in a way that the $\rho^{\text {th }}$ spatial harmonic of the stator magnetomotive force distribution can be directly evaluated from the current vector of the same order $\left(\rho^{\text {th }}\right)$. This approach, commonly employed in modeling multiphase machines, allows to simplify the analysis to a reduced number of field harmonics (i.e., current space vectors). Each current space vector, determined by (2), is built as a sum of the phase currents multiplied by a unit vector that is rotated according to the order of the space $\left(\rho^{\text {th }}\right)$ and the angular position of the magnetic axis of each phase.

As an example, Fig.2(a) illustrates the machine geometry of a triple three-phase MSPM machine, highlighting the phases of the different sectors with different colors, and the coils of the three phases of the same sector with different shades of the same color. The positive and negative terminals of each phase are identified with a "+" (or a "--") in addition to the name of the phase displayed into each slot.

Fig. 2(b) depicts the magnetic axes of the same machine. As it can be noticed, the magnetic axes are represented in terms of their angular position in mechanical radians. It is worth to note that the magnetic axes of all the phases $V$ and $W$ are shown, in Fig. 2(b), in the opposite direction with respect of the convention given by the direction of the phases (as highlighted by the "-" preceding the name of each axis).

The main harmonics of the stator magnetomotive force, responsible for the torque and force production, must be identified to properly select the related current space vectors in (2). For an isotropic permanent magnet rotor with $p$ pole pairs, it is well known that the torque is mainly generated by

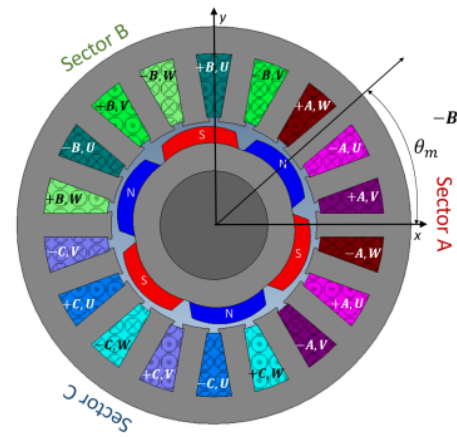

a)

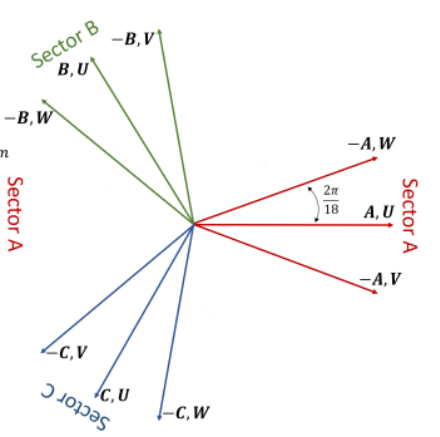

b)
Fig. 2 - Schematic of a triple-three-phase multi-sector winding. Machine schematic (a) and magnetic axes of the nine phases (b).

the $p^{\text {th }}$ harmonic of the stator magnetomotive force, and more precisely to the quadrature component of the $p^{\text {th }}$ current space vector in the rotor reference frame $\left(\bar{l}_{p} e^{-j p \vartheta_{m}}=i_{p, d}+j i_{p, q}\right)$. As far as the radial force production is concerned, the stator magnetomotive force harmonics of order $p+1$ and $p-1$ yield constant contributions to the force [18].

Consequently, the simultaneous control of both torque and radial force can be implemented as a function of the three current space vectors of order $p, p-1$ and $p+1$ as follows [48]:

$$
\begin{gathered}
T=k_{T} i_{p, q} \\
\bar{F}_{p-1}=k_{F, p-1} \bar{\iota}_{\mathrm{p}-1}^{*} e^{j p \vartheta_{m}} \\
\bar{F}_{p+1}=k_{F, p+1} \bar{\iota}_{\mathrm{p}+1} e^{-j p \vartheta_{m}} .
\end{gathered}
$$

Merging the two contributions in (4) and (5), the fundamental equation for the radial force control results as follows:

$$
\bar{F}=k_{F, p-1} \bar{l}_{\mathrm{p}-1}^{*} e^{j p \vartheta_{m}}+k_{F, p+1} \bar{\iota}_{\mathrm{p}+1} e^{-j p \vartheta_{m}} .
$$

Under the presented assumptions, equations (3) and (6), together with the equations of motion, are the main relationships describing the electromechanical behavior of the machine.

The peculiarity of a multi-sector multi-three-phase drive, as the one shown in Fig. 2, is the galvanic insulation of the three-phase sub-windings. This insulation permits to independently supply each sub-winding with a different inverter, allowing to define fault-tolerant and power-sharing strategies for the control of the overall drive. Therefore, the machine model must be extended accordingly by defining a link between the modular three-phase and the multiphase quantities, i.e., between the transformations (1) and (2). The link can be determined by introducing the new constants

$$
\begin{aligned}
& c_{m, \rho}=1-e^{-j\left(\frac{2 \pi}{3}+\rho \frac{2 \pi}{6 p}\right)}-e^{j\left(\frac{2 \pi}{3}+\rho \frac{2 \pi}{6 p}\right)} \\
& c_{n, \rho}=1-e^{j\left(\frac{2 \pi}{3}-\rho \frac{2 \pi}{6 p}\right)}-e^{-j\left(\frac{2 \pi}{3}-\rho \frac{2 \pi}{6 p}\right)} .
\end{aligned}
$$

Thence, (2) can be rewritten as a function of the threephase current space vectors in (1) as follows:

$$
\bar{l}_{\rho}=\frac{1}{3 p N_{T}} \sum_{T=1}^{N_{T}} \sum_{P=1}^{p}\left(\bar{l}_{T, P} c_{m, \rho}+\bar{l}_{T, P}^{*} c_{n, \rho}\right) e^{j \rho 2 \pi\left(\frac{T-1}{6 p N_{T}}+\frac{P-1}{p}\right)} .
$$

Equation (9), together with (3) and (6), intends to represent the effect that specific constraints on the currents of the various three-phase inverters have on the torque and radial 
force controls. For example, $\bar{\imath}_{T, P}$ is zero in case of a threephase sub-winding open-phase fault and it assumes defined values in case of a specific power-sharing request in the multiport-system architecture.

\section{Power-Sharing Algorithm for Multi-Sector PERMANENT Magnet Machines}

The implementation of a power-sharing algorithm for a synchronous machine with surface mounted permanent magnets can be simplified to a torque-sharing algorithm, or, in other terms, to the implementation of different set points for the $q$-axis components of the current vectors of each threephase sub-system $\left(\bar{l}_{T, P} e^{-j p \vartheta_{m}} e^{j \frac{2 \pi(T-1)}{6 N_{T}}}=i_{T, P, d}+j i_{T, P, q}\right)$.

\section{A. Radial Force Control in Multi-Sector Drives under Power-Sharing Operation}

Power-sharing algorithms and faults in multi-sector machines introduce unbalances in the machine symmetry which generate undesired radial forces [49]. Therefore, the implementation of a power-sharing algorithm for this machine topology requires additional considerations. In particular, recent works proposed the $d-q$ axes decoupling approach for the development of current sharing controls [13]-[15]. Following a similar approach, the three-phase current space vectors of the MSPM drive can be written in the $d-q$ axes reference frame, by introducing suitable sharing coefficients $K_{T, P, d}$ and $K_{T, P, q}$, as below:

$$
\bar{\iota}_{T, P}=N_{T} p\left(K_{T, P, d} i_{d}+j K_{T, P, q} i_{q}\right)
$$

assuming the following constraints:

$$
\sum_{T=1}^{N_{T}} \sum_{P=1}^{p} K_{T, P, d}=1, \quad \sum_{T=1}^{N_{T}} \sum_{P=1}^{p} K_{T, P, q}=1 .
$$

Substituting (10) in (9), the space vector equations can be rewritten as follows:

$$
\begin{gathered}
\bar{\iota}_{\rho}=\left(\bar{K}_{\rho, d_{+}} c_{m, \rho} e^{j p \vartheta_{m}}+\bar{K}_{\rho, d_{-} c_{n, \rho}} e^{-j p \vartheta_{m}}\right) i_{d}+ \\
+j\left(\bar{K}_{\rho, q_{+}} c_{m, \rho} e^{j p \vartheta_{m}}-\bar{K}_{\rho, q_{-}} c_{n, \rho} e^{-j p \vartheta_{m}}\right) i_{q}
\end{gathered}
$$

where the current-sharing complex control variables $\bar{K}_{\rho, d(q)_{ \pm}}$ are defined as follows:

$$
\bar{K}_{\rho, d(q)_{ \pm}}=\sum_{T=1}^{N_{T}} \sum_{P=1}^{p} K_{T, P, d(q)} e^{j 2 \pi \frac{\rho \mp p(T-1)}{p} \frac{N_{T}}{6 N}} e^{j \rho 2 \pi \frac{P-1}{p}} .
$$

Once the current-sharing variables in (13) are defined, the space vectors (12) can be evaluated. Consequently, it is possible to determine the torque and force, by (3) and (6), and predict the electromechanical behavior of the machine.

Assuming a set of $q$-axis sharing coefficients and a reference torque (i.e., the $q$-axis currents), the radial force $\bar{F}_{s h}$ generated by the power-sharing control can be predicted. In fact, substituting (12) in (6), the radial force $\bar{F}_{s h}$ resulting from both the $q$-axis sharing coefficients and the value of $i_{q}$ can be expressed as follows:

$$
\bar{F}_{s h}=j\left[\begin{array}{l}
-k_{F, p-1}\left(\bar{K}_{p-1, q_{+}}^{*} c_{m, p-1}-\bar{K}_{p-1, q_{-}}^{*} c_{n, p-1} e^{j 2 p \vartheta_{m}}\right) \\
+k_{F, p+1}\left(\bar{K}_{p+1, q_{+}} c_{m, p+1}-\bar{K}_{p+1, q_{-}} c_{n, p+1} e^{-j 2 p \vartheta_{m}}\right)
\end{array}\right] i_{q} .
$$

The $d$-axis current $i_{d}$ and sharing coefficients $\bar{K}_{\rho, d}$ can be determined according to the desired value of the radial force $\bar{F}$ acting on the rotor by means of (6) and (14), i.e., as a function of the $q$-axis current $i_{q}$ and sharing coefficients $\bar{K}_{\rho, q_{ \pm}}$, as follows:

$\left[\begin{array}{l}k_{F, p-1}\left(\bar{K}_{p-1, d_{+}}^{*} c_{m, p-1}+\bar{K}_{p-1, d_{-}}^{*} c_{n, p-1} e^{j 2 p \vartheta_{m}}\right)+ \\ +k_{F, p+1}\left(\bar{K}_{p+1, \mathrm{~d}_{+}} c_{m, p+1}+\bar{K}_{p+1, \mathrm{~d}_{-}} c_{n, p+1} e^{-j 2 p \vartheta_{m}}\right)\end{array}\right] i_{d}=\bar{F}-\bar{F}_{s h}$.

The stator copper losses of the machine can be defined as follows:

$$
P_{J}=\frac{3 p^{2} N_{T}^{2}}{2} R_{S}\left(\sum_{T=1}^{N_{T}} \sum_{P=1}^{p} K_{T, P, d}^{2} i_{d}^{2}+\sum_{T=1}^{N_{T}} \sum_{P=1}^{p} K_{T, P, q}^{2} i_{q}^{2}\right) .
$$

Therefore, if the $q$-axis sharing coefficients are fixed by the power sharing algorithm the optimum repartition of the currents, to generate the desired force $\bar{F}$, can be found (analytically or numerically) from the minimization of the stator copper losses with respect to the $d$-axis sharing coefficients $K_{T, P, d}$.

The model presented up to this point is written in a generic form and can be applied to any MSPM machines with $N_{T}$ three-phase windings under each pole pair and $p$ pole pairs. In the next section (Section III-B) the equations of the behaviour of the radial force during power-sharing operation are rewritten for the considered triple-three-phase machine and are finally used for the definition of a bearingless control algorithm, in Section IV.

\section{B. Radial Force Control in a Triple-Three-Phase Multi- Sector Drive under Power-Sharing Operation}

Limiting the study to a multi-sector machine as the one depicted in Fig. 2, with three pole pairs $(p=3)$ and one threephase sub-winding under each pole pair $\left(N_{T}=1\right)$, the equations can be reduced to the space vectors of order 2, 3 and 4 . For the sake of clarity, the three-phase windings are named with letters $A, B$ and $C$ rather than numbers 1,2 and 3, resulting in a current space vector $\bar{l}_{T}$ for each sub-winding $(T=A, B, C)$, defined as follows:

$$
\bar{\imath}_{T}=3\left(K_{T, d} i_{d}+j K_{T, q} i_{q}\right) .
$$

The current space vectors of the considered triple threephase machine can be defined from the more general equation (2) as follows:

$$
\begin{aligned}
\bar{\iota}_{\rho}=\frac{2}{9} & {\left[i_{A, U}-i_{A, V} e^{-j \rho \frac{2 \pi}{18}}-i_{A, W} e^{j \rho \frac{2 \pi}{18}}\right.} \\
& +\left(i_{B, U}-i_{B, V} e^{-j \rho \frac{2 \pi}{18}}-i_{B, W} e^{j \rho \frac{2 \pi}{18}}\right) e^{j \rho \frac{2 \pi}{3}} \\
& \left.+\left(i_{C, U}-i_{C, V} e^{-j \rho \frac{2 \pi}{18}}-i_{C, W} e^{j \rho \frac{2 \pi}{18}}\right) e^{j \rho \frac{4 \pi}{3}}\right] .
\end{aligned}
$$

The complex current-sharing control variables of the considered system are evaluated from (13) as follows: 


$$
\begin{aligned}
& \bar{K}_{3, d(q)_{ \pm}}= K_{A, d(q)}+K_{B, d(q)}+K_{C, d(q)} \\
& \bar{K}_{2, d(q)_{ \pm}}=\bar{K}_{d(q)}^{*} \\
& \bar{K}_{4, d(q)_{ \pm}}=\bar{K}_{d(q)}
\end{aligned}
$$

with the $\bar{K}_{d(q)}$ complex variable defined as:

$$
\bar{K}_{d(q)}=K_{A, d(q)}+K_{B, d(q)} e^{j \frac{2 \pi}{3}}+K_{C, d(q)} e^{-j \frac{2 \pi}{3}} .
$$

Also, the current space vectors responsible for the torque and radial force production are evaluated combining (19) with (12) as follows:

$$
\begin{gathered}
\bar{\iota}_{2}=\bar{K}_{d}^{*}\left(c_{m, 2} e^{j 3 \vartheta_{m}}+c_{n, 2} e^{-j 3 \vartheta_{m}}\right) i_{d}+ \\
j \bar{K}_{q}^{*}\left(c_{m, 2} e^{j 3 \vartheta_{m}}-c_{n, 2} e^{-j 3 \vartheta_{m}}\right) i_{q} \\
\bar{\iota}_{3}=\left(K_{A, d}+K_{B, d}+K_{C, d}\right) e^{j 3 \vartheta_{m}} i_{d}+ \\
j\left(K_{A, q}+K_{B, q}+K_{C, q}\right) e^{j 3 \vartheta_{m}} i_{q} \\
\bar{\imath}_{4}=\bar{K}_{d}\left(c_{m .4} e^{j 3 \vartheta_{m}}+c_{n, 4} e^{-j 3 \vartheta_{m}}\right) i_{d}+ \\
j \bar{K}_{q}\left(c_{m, 4} e^{j 3 \vartheta_{m}}-c_{n, 4} e^{-j 3 \vartheta_{m}}\right) i_{q} .
\end{gathered}
$$

Equations (19)-(23) fully describe the machine currents under an independent choice of the $d$-axis and $q$-axis current sharing coefficients introduced in (10). If (19)-(23) are substituted in the expressions of the torque and radial force, (3) and (6), the electromechanical behavior of the considered drive can be summarized by the following relationships:

$$
\begin{aligned}
T & =k_{T}\left(K_{A, q}+K_{B, q}+K_{C, q}\right) i_{q} \\
\bar{F} & =\left[\begin{array}{c}
k_{F, 2}\left(c_{m, 2}+c_{n, 2} e^{j 6 \vartheta_{m}}\right)+ \\
+k_{F, 4}\left(c_{m, 4}+c_{n, 4} e^{-j 6 \vartheta_{m}}\right)
\end{array}\right] \bar{K}_{d} i_{d}+ \\
& +j\left[\begin{array}{c}
-k_{F, 2}\left(c_{m, 2}-c_{n, 2} e^{j 6 \vartheta_{m}}\right)+ \\
+k_{F, 4}\left(c_{m, 4}-c_{n, 4} e^{-j 6 \vartheta_{m}}\right)
\end{array}\right] \bar{K}_{q} i_{q} .
\end{aligned}
$$

\section{Case study: Radial Forces in a Triple-Three-Phase Multi-Sector Drive Under Power Sharing Operation}

In order to validate the model used to develop the control architecture, and highlight its approximations, this paragraph proposes the analysis of a case study of multi-sectored drive operating under unbalanced operation.

Observing (25), and assuming that the considered permanent magnet machine with isotropic rotor is operated with a zero $d$-axis current $\left(i_{d}=0\right)$, it is possible to highlight the behavior of the resulting radial force. The latter appears, for example, in case of an open phase fault of the drive.

More in detail, there is a first contribution of the radial force in the second term of (25) which has a constant value $\bar{F}_{d c}$, and a second one that is composed by the sum of a rotating term and a contrarotating one at twice the electrical frequency of the drive $\left(6 f_{m}=2 f_{e}\right)$. Also, due to the properties of rotating vectors, the second contribution results in the sum of a pulsating force $\bar{F}_{\text {pulse }} \cos \left(2 \omega_{e} t+\varphi\right)$ and a rotating one $\bar{F}_{r o t} e^{ \pm j 2 \omega_{e} t}$, both at twice the electrical frequency.

Consequently, during the power-sharing operation of a multi-sector multi-three-phase drive (without controlling the radial forces), the trajectory of the radial force caused by the unbalance of the power flows would be qualitatively represented as follows:

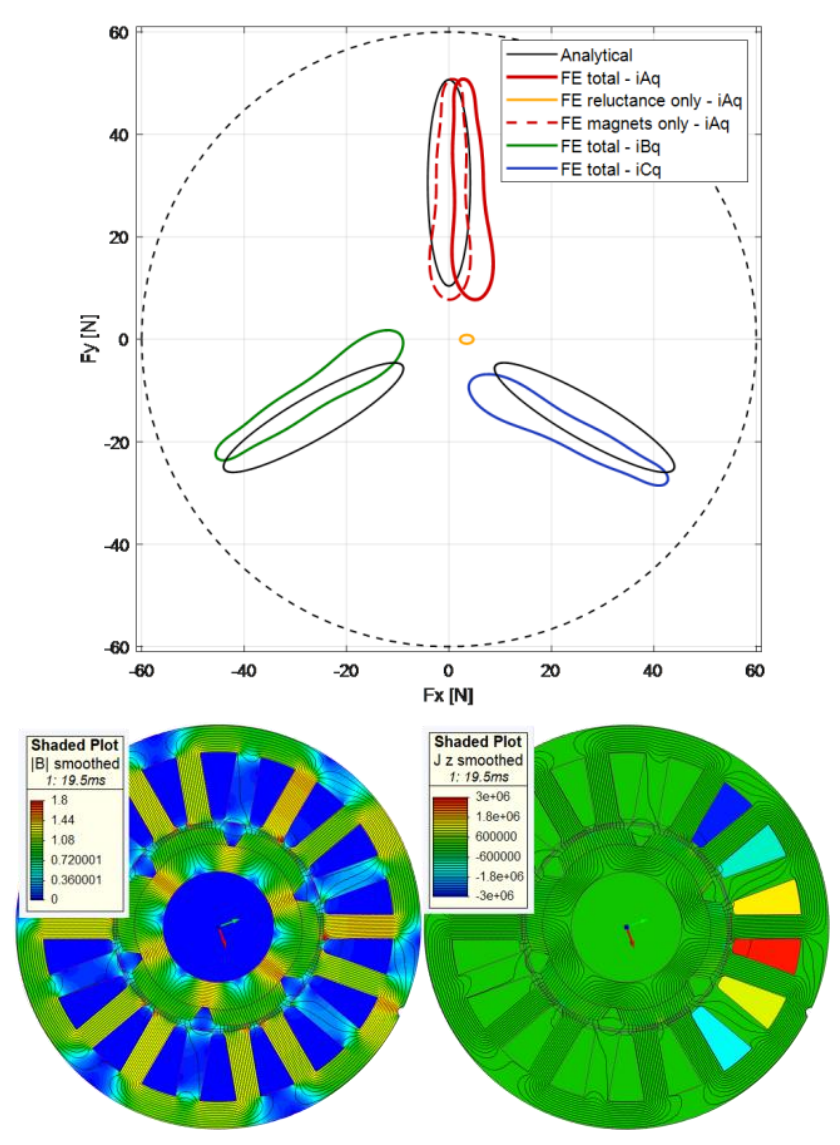

Fig. 3 - Comparison between analytical and finite element results of the radial force trajectory while supplying only one sector with $q$-axis current (top); flux and current density distribution when only sector $A$ is supplied (bottom).

$$
\bar{F}_{s h}(t)=\bar{F}_{d c}+\bar{F}_{\text {pulse }} \cos \left(2 \omega_{e} t+\varphi\right)+\bar{F}_{\text {rot }} e^{ \pm j 2 \omega_{e} t}
$$

This behavior has been validated by means of finite element simulations in MagNet 2D (Mentor). Fig. 3 shows the finite element trajectories of the radial force produced when controlling the machine with 11.5 Apk q-axis current in one sector only $(A, B$ or $C)$.

The finite element results are compared with the ones predicted by equation (26). The mismatch between finite element and analytical results is mainly caused by the reluctance force, not included in the presented model.

In fact, supplying only sector $A$ the reluctance force generates an additional attraction force of the rotor in the direction of sector $A$, i.e., in the $x$ direction. This contribution is displayed in Fig. 3 (the central circle highlighted in orange color). The reluctance force contribution has been obtained by means of additional finite element simulations where the magnets have been substituted with air.

Finally, the reluctance contribution has been subtracted from the total radial force, to generate the red dashed trajectory that considers only for the radial force generated by the interaction of the stator magnetomotive force with the rotor magnets. The comparison shows that the main contributions are well predicted. The small difference between the analytical and finite element results can be attributed to the higher order harmonics of the magnets and stator magnetomotive force distributions.

It can be concluded that (25)-(26) provide a valid tool to 


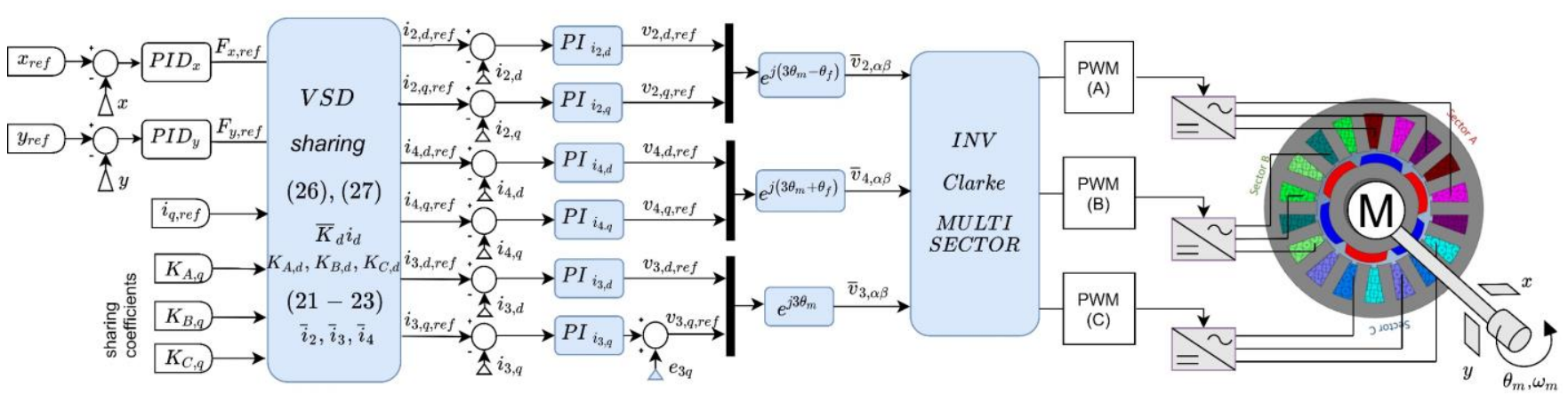

Fig. 4 - Control diagram of a triple-three-phase MSPM machine for bearingless operation under power-sharing working condition.

evaluate the main radial force trajectories during the powersharing operation in a permanent magnet machine with a multi-sector multi-three-phase winding arrangement.

As a result of this theoretical analysis, the control of multisector permanent magnet drives under (unbalanced) powersharing operation is more likely to produce noise and vibrations due to the generation of significant radial force components, unless these forces are compensated by implementing a specific control strategy.

The reluctance and higher order contributions to the radial force are the cause of the discrepancy between the FE calculated force and the analytically estimated one. A more complex model could be developed to consider in detail all the contributions to the radial force production, including also the reluctance component [45]. However, this would further increase the control algorithm complexity. Therefore, in the following the reluctance and higher order contributions to the radial force are neglected. It is worth mentioning that the aforementioned assumptions would not be valid for machines where the effect of the reluctance force is prevalent, in which case the development of the control architecture requires a different approach.

\section{BEARINGLESS CONTROL WITH POWER-SHARING ALGORITHM FOR PERMANENT MAGNET MULTI-SECTOR DRIVES}

In this section, a control strategy which simultaneously allows the bearingless and the power-sharing operation of a multi-sector multi-three-phase permanent magnet synchronous machine is implemented.

On the one hand, as commented in the Section III, the power-sharing operation of such electrical machine topology leads to the generation of an unbalanced radial force. On the other hand, the bearingless operation of a multi-sector machine does not guarantee that the overall managed power is equally shared among the different three-phase winding systems (the $q$-axis currents are not necessarily balanced). Consequently, the proposed control strategy can be also employed to reduce the radial force produced during the power-sharing operation or to minimize the unbalance of the power flows during the bearingless operation.

During the power-sharing operation the $q$-axis components of the inverter currents are generally controlled to different set points. The radial force that results from this unbalanced operation is represented by the second contribution in (25), highlighted in (26), and it cannot be altered. Therefore, the control of the radial force must be implemented by exploiting the $d$-axis components of the inverters' currents in the most efficient manner. In particular, the optimization strategy developed in this work leads to the minimization of the stator Joule losses in the whole multiphase winding.

Focusing on the force equation (25), the $d$-axis components of the inverters' currents are function of the $d$ axis current sharing coefficients and must be controlled according to both the desired reference force $\bar{F}_{\text {ref }}$ and the uncontrolled force resulting from the power sharing. Assuming a power-sharing contribution to the force $\bar{F}_{s h}$, the control of the $d$-axis current components must agree to the following equality:

$$
\bar{K}_{d} i_{d}=\frac{\bar{F}_{r e f}-\bar{F}_{s h}}{k_{F, 2}\left(c_{m, 2}+c_{n, 2} e^{j 6 \vartheta_{m}}\right)+k_{F, 4}\left(c_{m, 4}+c_{n, 4} e^{-j 6 \vartheta_{m}}\right)} .
$$

To ensure that the stator Joule losses needed for the radial force control are minimized, it is possible to explicit the additional losses associated with the $d$-axis currents in (16) as follows:

$$
P_{J, a d d}=\frac{27}{2} R_{s}\left(K_{A, d}^{2}+K_{B, d}^{2}+K_{C, d}^{2}\right) i_{d}^{2} .
$$

Therefore, for a given reference value of $\bar{K}_{d} i_{d}$ in (27), the minimum for (28), i.e. the optimum values for the $d$-axis sharing coefficients, can be found analytically. However, owing to the particular representation of the complex sharing coefficients in (20), it follows that an approach similar to the one used to define the inverse Clarke transformation of a polyphase system can be applied to the complex variable $\bar{K}_{d}$. The optimum is simply given by the analytical solution with zero common mode component $\left(K_{A, d}+K_{B, d}+K_{C, d}=0\right)$, as follows:

$$
K_{A, d}=\Re\left\{\bar{K}_{d}\right\} ; K_{B, d}=\Re\left\{\bar{K}_{d} e^{-j \frac{2 \pi}{3}}\right\} ; K_{C, d}=\Re\left\{\bar{K}_{d} e^{j \frac{2 \pi}{3}}\right\} .
$$

Therefore, by solving (27) and implementing (29), the machine force control under power-sharing operation is fully defined. In fact, the values of the $d$-axis sharing coefficients in (29) with the value of $\bar{K}_{d} i_{d}$ in (27) can be replaced in (21)(23), together with the $q$-axis sharing coefficients and $i_{q}$ value resulting from the power-sharing algorithm. By doing so, the set points for the three current space vectors $\bar{l}_{2}, \bar{l}_{3}$ and $\bar{l}_{4}$ are uniquely determined as a function of: $\bar{F}_{r e f}, i_{q, r e f}$ and the power-sharing coefficients $K_{A, q}, K_{B, q}$, and $K_{C, q}$.

Fig. 4 shows the control diagram of the multi-sector drive. The $x$ - $y$ components of the radial force request are determined by the respective PID controllers, acting to eliminate the $x-y$ position errors. At the same time, the $i_{q, \text { ref }}$ reference current is shared among the three inverters according to the respective 
TABLE I

MACHINE PARAMETERS

\begin{tabular}{clc}
\hline \hline Symbol & Quantity & Value \\
\hline$P_{\text {rated }}$ & Rated power & $1.5 \mathrm{~kW}$ \\
$n_{m}$ & Rated speed $n_{m}=\frac{60 \omega_{m}}{2 \pi}$ & $3000 \mathrm{rpm}$ \\
$p$ & Pole pair number & 3 \\
$m$ & Number of phases & 9 \\
$N_{T}$ & Number of three-phase systems of each & 1 \\
& pole pair & \\
$N_{c}$ & Number of turns per coil & 22 \\
$i_{p k}$ & Maximum peak current & $20 \mathrm{~A}$ \\
& Airgap radius & $24.25 \mathrm{~mm}$ \\
$\sigma$ & Axial active length & $90 \mathrm{~mm}$ \\
$\mathrm{WR}$ & Mass of the rotor & $2 \mathrm{~kg}$ \\
$P M$ & Magnets material & $\mathrm{NdFeB}$ \\
$L d, L q$ & $d$ - $q$ axis inductances of each sector & $0.52 \mathrm{mH}$ \\
$k_{U}$ & Unstable position stiffness & $655 \mathrm{~N} / \mathrm{mm}$ \\
$k_{F, 2}$ & Radial force constant space 2 & $9.60 \mathrm{~N} / \mathrm{A}$ \\
$k_{F, 4}$ & Radial force constant space 4 & $17.85 \mathrm{~N} / \mathrm{A}$ \\
\hline \hline
\end{tabular}

coefficients $K_{A, q}, K_{B, q}$, and $K_{C, q}$. The "VSD sharing" block implements equations (26), (27) and (29) to compute the reference current space vectors (21)-(23). Overall, there are six current PI regulators which identify the voltages required to track the reference values of the three independent current space vectors of the machine. Finally, the reference voltage space vectors are converted in their respective three-phase voltage vectors, used to define the modulating signals for the PWM implementation in the inverters $A, B$ and $C$.

\section{SiMULATION AND EXPERIMENTAL RESULTS}

Numerical simulations and experimental tests have been performed to validate the model of the drive and the developed control strategy. Table I summarizes the main machine parameters for the prototyped sectored triple-threephase permanent magnet machine.

The simulations are based on a Matlab-Simulink model which makes use of look-up tables to represent the electromechanical behavior of the machine. In particular, the relationships between the electromagnetic inputs (phase currents) and outputs (linked fluxes, torque, and force components) are estimated through non-linear FE 2D simulations of the machine. For each static simulation, the rotor is rotated by a small angle and each sector is fed with a different current value. The values calculated for the linked fluxes, $x-y$ force components and torque are stored in the form of lookup table. Finally, this lookup table is used to represent the numerical model of the electrical machine implemented in Simulink.

The experimental tests have been carried out on a bearingless drive with two mechanical degrees of freedom, limited by a back-up bearing with $150 \mu \mathrm{m}$ of clearance on the front side of the machine. Fig. 5 shows the machine prototype. A self-alignment bearing allows avoiding the axial and $x-y$ displacement of the rotor on the rear side of the shaft, hence avoiding the tilting movement of the rotor during the two degrees of freedom bearingless control. The position of the shaft is measured by means of two eddy current displacement sensors on the $x$ and $y$ directions, orthogonal to the rotation axis of the rotor. The control algorithm is implemented on a custom control platform based on the Microzed board, equipped with the Xilinx Zynq System-on-Chip [50].

The currents and power flows obtained by means of

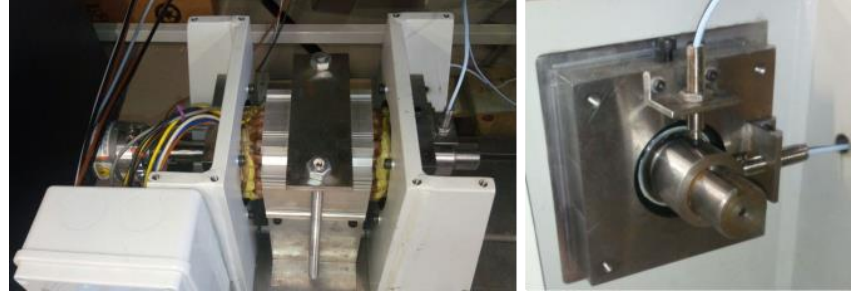

Fig. 5 - Prototype of bearingless multi-sector permanent magnet machine (left) and $x-y$ displacement sensors (right).

simulation and experimental tests are shown in Fig. 6 and Fig. 7 , respectively. For better comparison, both simulation and experimental results assume the same operating condition, i.e., $3000 \mathrm{rpm}$ and $1 \mathrm{Nm}$ load torque, $100 \mathrm{~V}$ DC link voltage.

During the test, four meaningful sharing scenarios have been performed. These scenarios are listed in terms of sharing coefficients $\left(K_{A, q}, K_{B, q}, K_{C, q}\right)$ and providing the related time frames (in square brackets), as follows:

1. Equal distribution of the power $\left(K_{A, q}=K_{B, q}=K_{C, q}=\right.$ 1/3), [0-0.05s and 0.125-0.15s].

2. Distribution of the power between inverters $A$ and $B$, and zero power set point for inverter $C\left(K_{A, q}=K_{B, q}=\right.$ $\left.0.5 ; K_{C, q}=0\right)$, [0.05-0.075s].

3. Equal distribution of the power between inverters $A$ and $B$ while $C$ has an opposite set point $\left(K_{A, q}=K_{B, q}=\right.$ $\left.1 ; K_{C, q}=-1\right)$, as in Fig. 1, [0.075-0.1s].

4. Inverter A keeps the same set point, whereas $B$ and $C$ double their sharing coefficients, recirculating a higher power $\left(K_{A, q}=1 ; K_{B, q}=2 ; K_{C, q}=-2\right)$, [0.1-0.125s].

According to equation (17) the $q$-axis currents of the three inverters $(A, B, C)$ in Fig. 6-7 follow the values assumed by their sharing coefficients $\left(K_{A, q}, K_{B, q}, K_{C, q}\right)$. As expected, also the respective power flows are distributed according to these set points, validating the assumption of the control algorithm.

The distortion of the currents in the simulation results of Fig. 6 is caused by all the electromagnetic phenomena that are not included in the model and control algorithm. Among these, the authors mainly attribute the distortion to cogging torque, slotting effect, and higher order field harmonics.

The experimental results (Fig. 7) are in good agreement with the simulation ones (Fig. 6). The small differences can be ascribed to additional phenomena such as converter nonlinearities and noise in the measurements of the currents and the rotor position.

Finally, Fig. 8 shows the values of the $x$ and $y$ displacements of the shaft from its center. The trajectory is obtained from the measurements acquired during the same experimental test of Fig. 7 and for the overall time frame [0$0.15 s]$. The external circumference of Fig 8 (dashed) represents the maximum displacement allowed by the backup bearing. Also, an internal circumference with a diameter of 60 $\mu m$ has been introduced to highlight the good performance of the bearingless operation during all the considered powersharing scenarios.

Fig. 9 shows the experimental results carried out in similar test conditions. In this test, the machine is controlled during a speed transient. The reference torque is limited at $5 \mathrm{Nm}$ and 3 $\mathrm{Nm}$ before and after the setting of the unbalance of the power flows, respectively. The sharing coefficients are set equal 

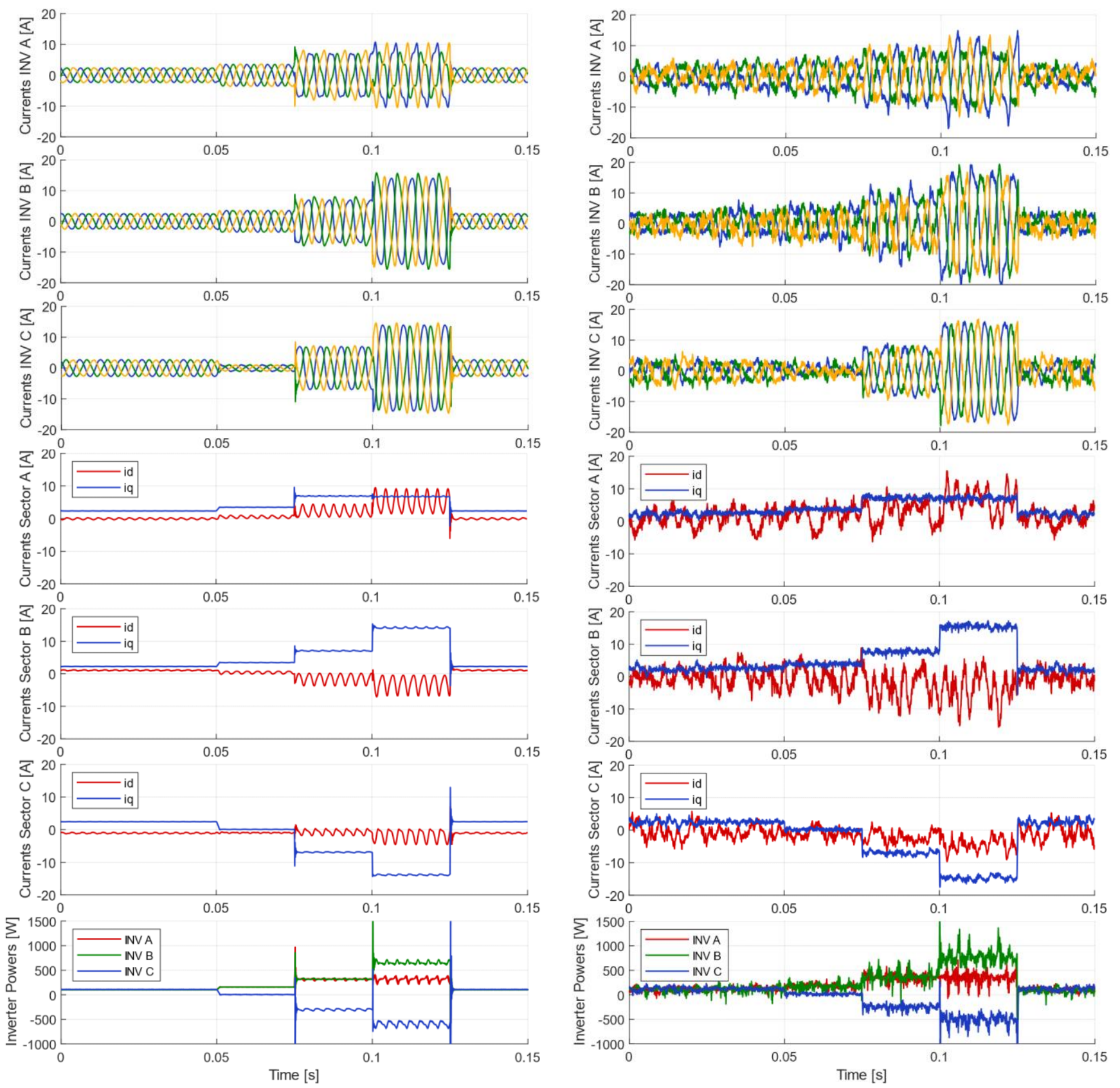

Fig. 6 - Simulation Results at $3000 \mathrm{rpm}$ under power-sharing and bearingless operation of the drive. From the top to the bottom: phase currents, $d-q$ axis currents and inverter power flows.

$\left(K_{A, q}=K_{B, q}=K_{C, q}=1 / 3\right),[0.9-1.0 s]$, and with a zero power set point for inverter $C\left(K_{A, q}=K_{B, q}=0.5 ; K_{C, q}=0\right)$, [1.0-1.1s]. During the time step 1.0-1.1s the torque limit is reduced to avoid an overload of the sub-windings and to keep the phase currents around their rated values.

Comparing the results of Fig. 7 and Fig. 9 it is possible to appreciate that there is less distortion in the phase currents when the load is higher and the unbalance in the power flows is lower. The trajectory of the $x-y$ rotor displacement during this test is not illustrated, because it does not significantly differ from the one shown in Fig. 8.

The tests of the bearingless drive under different powersharing conditions validate the model and the proposed control approach.

Fig. 7 - Experimental Results at 3000 rpm under power-sharing and bearingless operation of the drive. From the top to the bottom: phase currents, $d-q$ axis currents and inverter power flows.

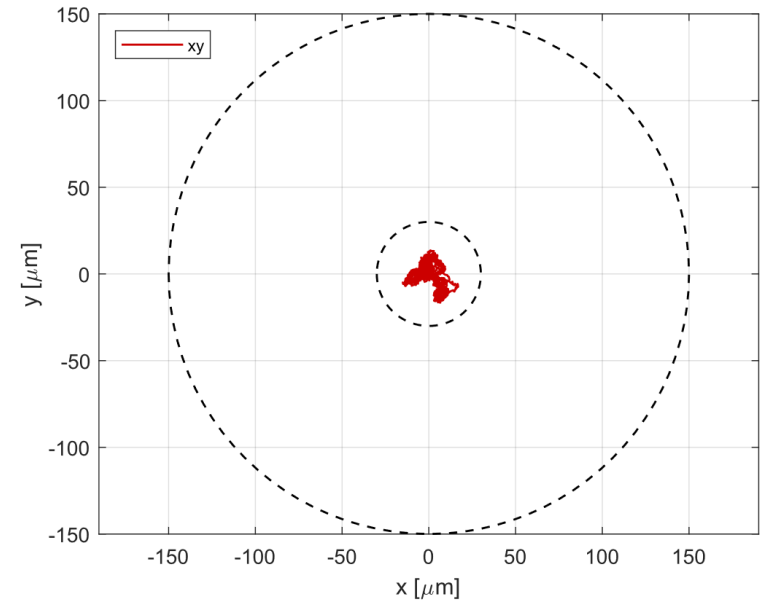

Fig. 8 - Experimental Results at 3000 rpm under power-sharing and bearingless operation of the drive. Trajectory of the $x-y$ rotor displacement during the same test whose results are shown in Fig.7. 


\section{CONCLUSION}

In this paper, a control strategy which simultaneously allows the bearingless and the power-sharing operation of a multi-sector multi-three-phase permanent magnet synchronous machine has been presented. The control methodology is based on the vector space decomposition approach, which has been extended to multi-sector permanent magnet synchronous machines working under power-sharing operation. The general modeling methodology has been introduced and a control algorithm which also minimizes the stator copper losses has been defined. The performance of the proposed control strategy has been verified via dynamic simulation and experimentally validated.

Experimental tests have been carried out on a prototyped sectored triple-three-phase machine, assembled on an instrumented test rig which allows the bearingless operation with two degrees of freedom. The obtained results confirmed the validity of the proposed theory, showing stable control of the bearingless drive under different power-sharing scenarios.

This work aims to contribute to the development of advanced control systems employing multiphase drives in the field of bearingless and multiport applications. In fact, the proposed control strategy can be employed with three different objectives:

- simultaneously implement a bearingless and a controlled power-sharing operation;

- reduce the radial force produced during the power-sharing control;

- minimize the unbalance of the power flows during the bearingless operation.

\section{REFERENCES}

[1] V. Yaramasu, A. Dekka, M. J. Durán, S. Kouro, and B. Wu, "PMSGbased wind energy conversion systems: survey on power converters and controls," IET Electr. Power Appl., vol. 11, no. 6, pp. 956-968, 2017.

[2] J. Dai, S. W. Nam, M. Pande, and G. Esmaeili, "Medium-Voltage Current-Source Converter Drives for Marine Propulsion System Using a Dual-Winding Synchronous Machine," IEEE Trans. Ind. Appl., vol. 50, no. 6, pp. 3971-3976, 2014.

[3] G. Sulligoi, A. Tessarolo, V. Benucci, A. M. Trapani, M. Baret, and F. Luise, "Shipboard Power Generation: Design and Development of a Medium-Voltage dc Generation System," IEEE Ind. Appl. Mag., vol. 19, no. 4, pp. 47-55, 2013.

[4] B. Gamble, G. Snitchler, and T. MacDonald, "Full Power Test of a 36.5 MW HTS Propulsion Motor," IEEE Trans. Appl. Supercond., vol. 21, no. 3, pp. 1083-1088, 2011

[5] D. Sarafianos, D. X. Llano, S. S. Ghosh, R. A. McMahon, S. Pickering, and T. J. Flack, "Control Strategy for a Multiphase LundellAlternator/Active-Rectifier System in $14 \mathrm{~V}$ Automotive Power Systems," IEEE Trans. Transp. Electrif., vol. 5, no. 2, pp. 347-355, 2019

[6] R. Bojoi, A. Cavagnino, M. Cossale, and A. Tenconi, "Multiphase Starter Generator for a 48-V Mini-Hybrid Powertrain: Design and Testing," IEEE Trans. Ind. Appl., vol. 52, no. 2, pp. 1750-1758, 2016.

[7] E. Levi, "Advances in Converter Control and Innovative Exploitation of Additional Degrees of Freedom for Multiphase Machines," IEEE Trans. Ind. Electron., vol. 63, no. 1, pp. 433-448, 2016.

[8] F. Barrero and M. J. Duran, "Recent Advances in the Design, Modeling, and Control of Multiphase Machines-Part I," IEEE Trans. Ind. Electron., vol. 63, no. 1, pp. 449-458, 2016.

[9] F. Barrero and M. J. Duran, "Recent Advances in the Design, Modeling, and Control of Multiphase Machines-Part II," IEEE Trans. Ind. Electron., vol. 63, no. 1, pp. 459-468, 2016.

[10] V. Yaramasu, B. Wu, P. C. Sen, S. Kouro, and M. Narimani, "Highpower wind energy conversion systems: State-of-the-art and emerging technologies," Proc. IEEE, vol. 103, no. 5, pp. 740-788, 2015.

[11] S. S. Gjerde, P. K. Olsen, K. Ljøkelsøy, and T. M. Undeland, "Control

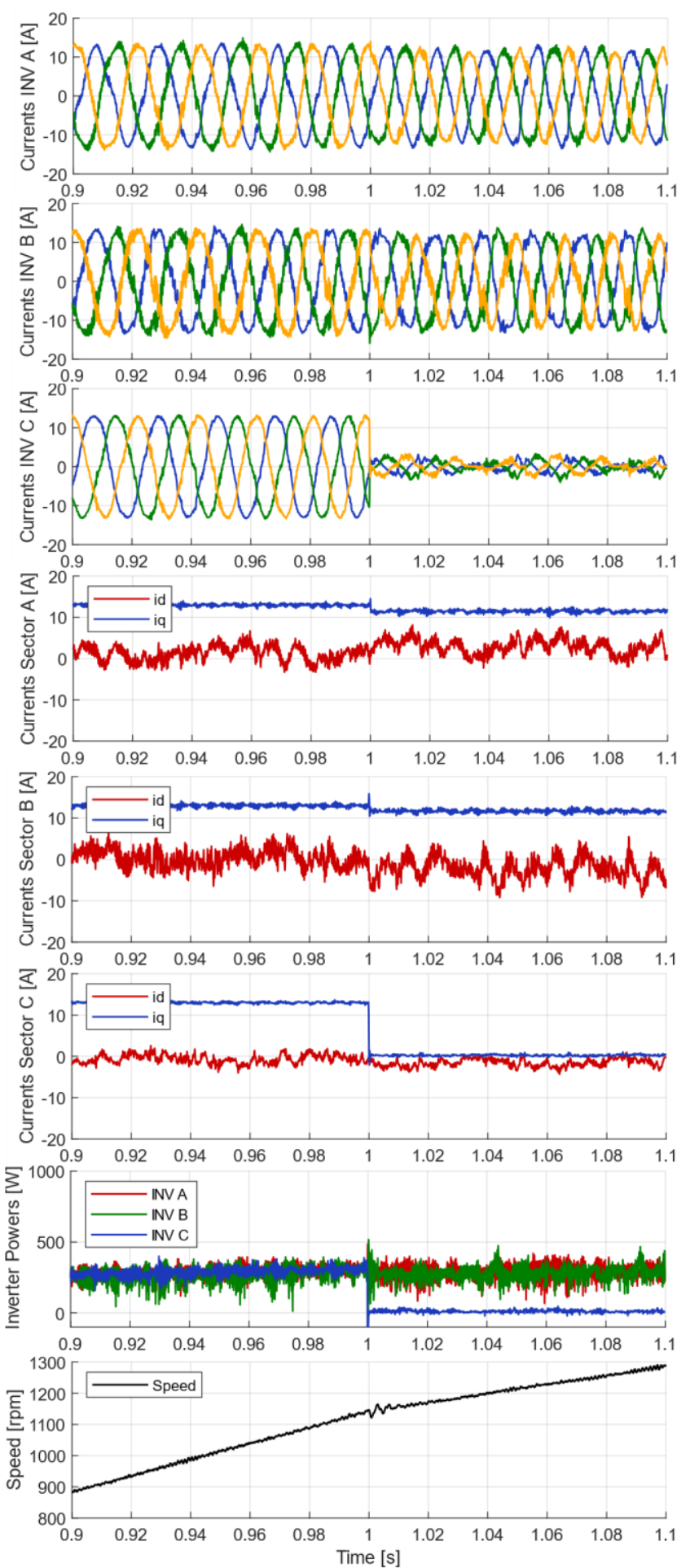

Fig. 9 - Experimental Results during a speed transient under powersharing and bearingless operation of the drive. From the top to the bottom: phase currents, $d-q$ axis currents, inverter power flows and speed.

and Fault Handling in a Modular Series-Connected Converter for a Transformerless $100 \mathrm{kV}$ Low-Weight Offshore Wind Turbine," IEEE Trans. Ind. Appl., vol. 50, no. 2, pp. 1094-1105, 2014.

[12] J. W. Bennett, G. J. Atkinson, B. C. Mecrow, and D. J. Atkinson, "FaultTolerant Design Considerations and Control Strategies for Aerospace Drives," IEEE Trans. Ind. Electron., vol. 59, no. 5, pp. 2049-2058, 2012.

[13] M. J. Duran, I. González-Prieto, A. González-Prieto, and F. Barrero, "Multiphase Energy Conversion Systems Connected to Microgrids With Unequal Power-Sharing Capability," IEEE Trans. Energy Convers., vol. 32, no. 4, pp. 1386-1395, 2017.

[14] I. Subotic, O. Dordevic, J. B. Gomm, and E. Levi, “Active and Reactive Power Sharing Between Three-Phase Winding Sets of a Multiphase 
Induction Machine," IEEE Trans. Energy Convers., vol. 34, no. 3, pp 1401-1410, 2019

[15] G. Sala, M. Mengoni, G. Rizzoli, L. Zarri, and A. Tani, "Decoupled dq Axes Current Sharing Control of Multi Three-Phase Induction Machines," IEEE Trans. Ind. Electron., p. 1, 2019.

[16] A. Galassini, A. Costabeber, M. Degano, C. Gerada, A. Tessarolo, and R. Menis, "Enhanced Power Sharing Transient With Droop Controllers for Multithree-Phase Synchronous Electrical Machines," IEEE Trans. Ind. Electron., vol. 66, no. 7, pp. 5600-5610, 2019.

[17] P. K. Hermann, "A radial active magnetic bearing," London Patent 1 478868.

[18] M. T. and D. G. D. A. Chiba, T. Fukao, O. Ichikawa, M. Oshima, Magnetic Bearings and Bearingless Drives. Elsevier, 2005.

[19] G. Schweitzer; E.H.Maslen, Magnetic Bearings: Theory, Design, and Application to Rotating Machinery. Berlin, Germany: Springer, 2009.

[20] J. Chen, J. Zhu, and E. L. Severson, "Review of Bearingless Motor Technology for Significant Power Applications," IEEE Trans. Ind. Appl., vol. 56, no. 2, pp. 1377-1388, 2020.

[21] W. Amrhein, W. Gruber, W. Bauer, and M. Reisinger, "Magnetic Levitation Systems for Cost-Sensitive Applications-Some Design Aspects," IEEE Trans. Ind. Appl., vol. 52, no. 5, pp. 3739-3752, 2016.

[22] A. Tüysüz, T. Achtnich, C. Zwyssig, and J. W. Kolar, “A 300 000-r/min Magnetically Levitated Reaction Wheel Demonstrator," IEEE Trans. Ind. Electron., vol. 66, no. 8, pp. 6404-6407, 2019.

[23] L. Yu, Z. Zhang, Y. Shi, and W. Lu, "Modeling and Analysis of Suspension Force of a New Bearingless Reluctance Machine With Independent DC Bias Winding," IEEE Trans. Magn., vol. 54, no. 11, pp. 1-5, 2018.

[24] J. Huang, B. Li, H. Jiang, and M. Kang, "Analysis and Control of Multiphase Permanent-Magnet Bearingless Motor With a Single Set of Half-Coiled Winding," IEEE Trans. Ind. Electron., vol. 61, no. 7, pp. 3137-3145, 2014.

[25] L. Chen and W. Hofmann, "Speed Regulation Technique of One Bearingless 8/6 Switched Reluctance Motor With Simpler Single Winding Structure," IEEE Trans. Ind. Electron., vol. 59, no. 6, pp. 2592-2600, 2012.

[26] M. D. Choudhury, F. Ahmed, G. Kumar, K. Kalita, and K. Tammi, "Design methodology for a special single winding based bearingless switched reluctance motor," J. Eng., vol. 2017, no. 7, pp. 274-284, Jul 2017.

[27] E. L. Severson, R. Nilssen, T. Undeland, and N. Mohan, "Design of Dual Purpose No-Voltage Combined Windings for Bearingless Motors," IEEE Trans. Ind. Appl., vol. 53, no. 5, pp. 4368-4379, 2017.

[28] X. Sun, L. Chen, and Z. Yang, "Overview of Bearingless PermanentMagnet Synchronous Motors," IEEE Trans. Ind. Electron., vol. 60, no. 12, pp. 5528-5538, 2013.

[29] H. Wang and F. Li, "Design Consideration and Characteristic Investigation of Modular Permanent Magnet Bearingless Switched Reluctance Motor," IEEE Trans. Ind. Electron., vol. 67, no. 6, pp. 43264337, 2020 .

[30] G. Valente, A. Formentini, L. Papini, C. Gerada, and P. Zanchetta, "Performance Improvement of Bearingless Multisector PMSM With Optimal Robust Position Control," IEEE Trans. Power Electron., vol. 34, no. 4, pp. 3575-3585, 2019.

[31] X. Sun, L. Chen, H. Jiang, Z. Yang, J. Chen, and W. Zhang, "HighPerformance Control for a Bearingless Permanent-Magnet Synchronous Motor Using Neural Network Inverse Scheme Plus Internal Model Controllers," IEEE Trans. Ind. Electron., vol. 63, no. 6, pp. 3479-3488, 2016.

[32] G. Sala, G. Valente, D. Gerada, P. Zanchetta, and C. Gerada, "Post-Fault Operation of Bearingless Multisector SPM Machines by Space Vector Control," IEEE Trans. Power Electron., vol. 35, no. 4, pp. 4168-4177, 2020

[33] X. Cao, H. Yang, L. Zhang, and Z. Deng, "Compensation Strategy of Levitation Forces for Single-Winding Bearingless Switched Reluctance Motor With One Winding Total Short Circuited," IEEE Trans. Ind. Electron., vol. 63, no. 9, pp. 5534-5546, 2016.

[34] H. Mitterhofer, W. Gruber, and W. Amrhein, "On the High Speed Capacity of Bearingless Drives," IEEE Trans. Ind. Electron., vol. 61, no. 6, pp. 3119-3126, 2014

[35] D. Steinert, T. Nussbaumer, and J. W. Kolar, "Slotless Bearingless Disk Drive for High-Speed and High-Purity Applications," IEEE Trans. Ind. Electron., vol. 61, no. 11, pp. 5974-5986, 2014.

[36] T. Baumgartner and J. W. Kolar, "Multivariable State Feedback Control of a 500 000-r/min Self-Bearing Permanent-Magnet Motor,' IEEE/ASME Trans. Mechatronics, vol. 20, no. 3, pp. 1149-1159, 2015

[37] M. Schuck, D. Steinert, T. Nussbaumer, and J. W. Kolar, "Ultrafast rotation of magnetically levitated macroscopic steel spheres," Sci. Adv., vol. 4, no. 1, p. e1701519, Jan. 2018

[38] H. S. Zad, T. I. Khan, and I. Lazoglu, "Design and Analysis of a Novel Bearingless Motor for a Miniature Axial Flow Blood Pump," IEEE Trans. Ind. Electron., vol. 65, no. 5, pp. 4006-4016, 2018.

[39] B. Warberger, R. Kaelin, T. Nussbaumer, and J. W. Kolar, "50Nm/2500-W Bearingless Motor for High-Purity Pharmaceutical Mixing," IEEE Trans. Ind. Electron., vol. 59, no. 5, pp. 2236-2247, 2012.

[40] P. Peralta, T. Wellerdieck, D. Steinert, T. Nussbaumer, and J. W. Kolar, "Ultra-High Temperature $\left(250{ }^{\circ} \mathrm{C}\right)$ Bearingless Permanent Magnet Pump for Aggressive Fluids," IEEE/ASME Trans. Mechatronics, vol. 22, no. 5, pp. 2392-2394, 2017.

[41] Z. Huang and J. Fang, "Multiphysics Design and Optimization of HighSpeed Permanent-Magnet Electrical Machines for Air Blower Applications," IEEE Trans. Ind. Electron., vol. 63, no. 5, pp. 27662774, 2016.

[42] G. Grandi, G. Serra, and A. Tani, "General Analysis of Multi-Phase Systems Based on Space Vector Approach," in 2006 12th International Power Electronics and Motion Control Conference, 2006, pp. 834-840.

[43] L. Serrano-Iribarnegaray, "Space phasor theory and control of multiphase machines through their decoupling into equivalent threephase machines," Electr. Eng., vol. 96, Mar. 2014.

[44] S. Serri, A. Tani, and G. Serra, "Analytical model of radial forces considering mutual effects between torque and levitation current space vectors in 5-phase PM bearingless motors," in IECON 2013 - 39th Annual Conference of the IEEE Industrial Electronics Society, 2013, pp. 5142-5147.

[45] G. Sala, D. Gerada, C. Gerada, and A. Tani, "Radial force control for triple three-phase sectored SPM machines. Part I: Machine model," in 2017 IEEE Workshop on Electrical Machines Design, Control and Diagnosis (WEMDCD), 2017, pp. 193-198.

[46] G. Sala, D. Gerada, C. Gerada, and A. Tani, "Radial force control for triple three-phase sectored SPM machines. Part II: Open winding fault tolerant control," in 2017 IEEE Workshop on Electrical Machines Design, Control and Diagnosis (WEMDCD), 2017, pp. 275-280.

[47] S. M. Mirić, R. V Giuffrida, D. Bortis, and J. W. Kolar, "Enhanced Complex Space Vector Modeling and Control System Design of Multiphase Magnetically Levitated Rotary-Linear Machines," IEEE J. Emerg. Sel. Top. Power Electron., vol. 8, no. 2, pp. 1833-1849, 2020.

[48] G. Sala et al., "Space Vectors and Pseudoinverse Matrix Methods for the Radial Force Control in Bearingless Multisector Permanent Magnet Machines," IEEE Trans. Ind. Electron., vol. 65, no. 9, pp. 6912-6922, 2018.

[49] M. Barcaro, N. Bianchi, and F. Magnussen, "Faulty Operations of a PM Fractional-Slot Machine With a Dual Three-Phase Winding," IEEE Trans. Ind. Electron., vol. 58, no. 9, pp. 3825-3832, 2011.

[50] A. Galassini, G. Lo Calzo, A. Formentini, C. Gerada, P. Zanchetta, and A. Costabeber, "uCube: Control platform for power electronics," in 2017 IEEE Workshop on Electrical Machines Design, Control and Diagnosis (WEMDCD), 2017, pp. 216-221. 


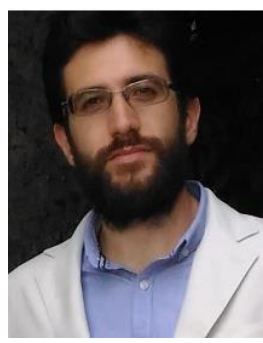

Giacomo Sala was born in Vercelli, Italy, in 1990. He received the B. Sc. in Powe Engineering in 2012 the M. Sc. degree with honors in Electrical Engineering in 2014 and the Ph. D. in Electrical Machines and Drives in 2018 from the University of Bologna, Italy. He worked as a researcher until 2019 in the Power Electronics, Machines and Control Group, Department of Electrical and Electronic Engineering, The University of Nottingham. Since 2019 he has been working as a researcher with the Department of Electrical, Electronic, and Information Engineering "Guglielmo Marconi" - DEI, University of Bologna, Italy, where he is currently employed as a Junior Assistant Professor, since 2020. His research interests include design, modelling and control of multiphase electrical machines, fault tolerant controls and fault diagnosis of electric drives.

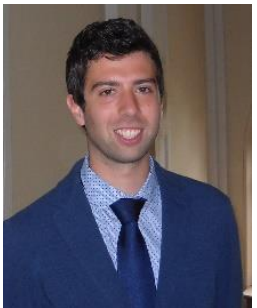

Giorgio Valente received the master degree (Hons) in electrical engineering from the University of Padova, Italy, in 2014, and the Ph.D. degree in electrical machines design and control from the University of Nottingham, Nottingham, U.K., in 2018. He then worked for two years as a Research Fellow with the Power Electronics, Machines and Control Group, University of Nottingham, U.K. He is now working as Electric Machine Design and Development Engineer in Romax Technology Ltd, Nottingham, U.K. His research interests include bearingless machines design and control, high speed machines, traction machines, and multiphysicsbased optimization of electrical machines.

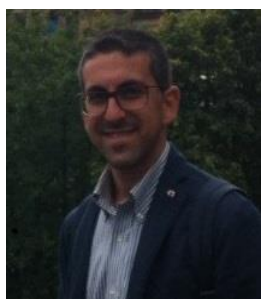

Mauro Di Nardo received the M.Sc. (Hons.) degree in electrical engineering from the Polytechnic University of Bari (Italy) in 2012, and the Ph.D. degree in electrical machine design from the University of Nottingham (UK) in 2017. From 2017 to 2019 he was head of the AROL research team within the Polytechnic University of Bari leading industrial R\&D projects on electrical drives design for mechatronics applications.

Since the 2019, he joined the Power Electronics and Machine Control Group of the University of Nottingham as Research Fellow.

His research interests are the analysis, modelling, and optimizations of electrical machines, including permanent magnet and synchronous reluctance topologies for automotive and aerospace sectors as well as induction motor for industrial applications.

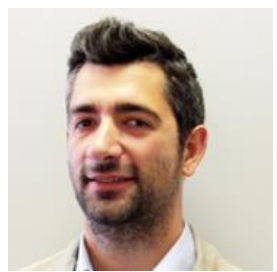

Michele Degano (M'15) received his Master's degree in Electrical Engineering from the University of Trieste, Italy, in 2011, and his Ph.D. degree in Industrial Engineering from the University of Padova, Italy, in 2015. Between 2014 and 2016, he was a post-doctoral researcher at The University of Nottingham, UK, where he joined the Power Electronics, Machines and Control (PEMC) Research Group. In 2016 he was appointed Assistant Professor in Advanced Electrical Machines, at The University of Nottingham, UK. He was promoted Associate Professor in 2020. His main research focuses on electrical machines and drives for industrial, automotive, railway and aerospace applications, ranging from small to large power. He is currently the PEMC Director of Industrial Liaison leading research projects for the development of future hybrid electric aerospace platforms and electric transports.

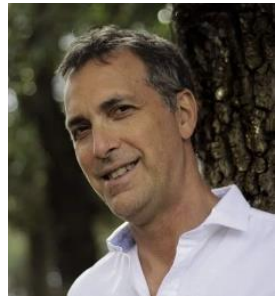

Pericle Zanchetta (M'00, SM'15, F'19) received his MEng degree in Electronic Engineering and his Ph.D. in Electrical Engineering from the Technical University of Bari (Italy) in 1993 and 1997 respectively. In 1998 he became Assistant Professor of Power Electronics at the same University. In 2001 he became lecturer in control of power electronics systems in the PEMC research group at the University of Nottingham - UK, where he is now Professor in Control of Power Electronics systems. $\mathrm{He}$ is also part time professor at the University of Pavia, Italy. He has published over 350 peer reviewed papers, he is past Chair of the IEEE-IAS Industrial Power Converter Committee IPCC (2016-2017), Transactions review chair for IPCC (2018-2021). He is also Chair of the IEEE-IAS Industrial Power Conversion Systems Department IPCSD 2020-2021. His research interests include control and optimization of power converters and drives, Matrix and multilevel converters. He is IEEE Fellow class 2019.

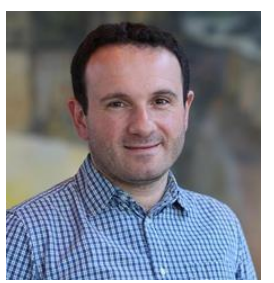

Chris Gerada (M'05) received the Ph.D. degree in numerical modeling of electrical machines from The University of Nottingham, Nottingham, U.K., in 2005. He subsequently worked as a Researcher with The University of Nottingham on high-performance electrical drives and on the design and modeling of electromagnetic actuators for aerospace applications. Since 2006, he has been the Project Manager of the GE Aviation Strategic Partnership. In 2008, he was appointed as a Lecturer in electrical machines; in 2011, as an Associate Professor; and in 2013, as a Professor at The University of Nottingham. His main research interests include the design and modeling of high-performance electric drives and machines. Prof. Gerada serves as an Associate Editor for the IEEE TRANSACTIONS ON INDUSTRY APPLICATIONS and is the past Chair of the IEEE IES Electrical Machines Committee. 